\title{
Black lives in the trauma room
}

\author{
Dominick Shelton ${ }^{1} \cdot$ Jacqueline Spence ${ }^{2}$
}

Received: 1 July 2020 / Accepted: 6 October 2020 / Published online: 10 December 2020

(c) Canadian Association of Emergency Physicians (CAEP)/ Association Canadienne de Médecine d'Urgence (ACMU) 2020

Keywords Anti-black racism · Black lives · Trauma

Shortly after the death of George Floyd, a Black emergency physician circulated an email to his EM colleagues. The events were weighing on his mind and the spotlight on antiBlack racism reminded him of his own victimization. The message included the following statement; "The events of the last several days have reminded me of the vulnerability of being Black, no matter where you are, no matter how privileged you are. I can still vividly recall the moment of being stopped by police as a teenager while riding my bike and the confusion and fear that it elicited. A concern that we always have in the ED is a 'gang banger' coming to finish off the job. Every time I walk past the police officers standing outside the trauma room, I hold my breath out of concern that they will mistake me for that 'gang banger' in disguise wearing scrubs".

What followed was a series of replies and conversations from colleagues that were supportive and poignant. The result of this recent uprising and protest of racism towards Blacks, particularly at the hands of police, is movement of society in the right direction. However, on an individual level, the biases that we all have need to be acknowledged and challenged to improve the well-being and health of all Black people. It is by honest self-reflection and courageous conversations that we disclose our own biases, empathize with the racist experiences of others and ultimately challenge racism when witnessed.

Let us delve into the trauma or resuscitation room to dissect anti-Black racism. When a young Black male is wheeled

Dominick Shelton

Dominick.shelton@sunnybrook.ca

Jacqueline Spence

Jacqueline.spence@tdsb.on.ca

1 Emergency Department, Sunnybrook Health Sciences Centre, 2075 Bayview Ave, Toronto, ON M4N 3M5, Canada

2 Toronto District School Board, 5050 Yonge St, 5th Floor, Toronto, ON M2N 5N8, Canada in, what are your first instinctive thoughts? Is it the same impartial response and desire to prevent death that you have towards a White victim of a motor vehicle collision? Or is it one of judgement that he may be a gang member and engages in illegal activity? Do you terminate resuscitation sooner than if the patient were a middle-aged White patient? If he is a victim of a gunshot wound and pulseless, would you be more or less likely to 'crack his chest'? Does his race make you more likely to practice this often-futile surgical procedure? Do you provide analgesia to the same extent as White trauma victims? Do you prefer Black trauma patients because you perceive the stakes as lower? When you break bad news to his family members, do you approach the encounter with empathy and regret? Or do you minimize your interaction and defer further details to a nurse or social worker? Do you cringe inside at the thought of being in a room with loud grieving Black people?

Unconscious bias is difficult to identify and acknowledge. Recognizing that we all have it is an important first step. Doctors are no different from the general population in our biases that are grounded in our past experiences. We like to think of ourselves as having fewer biases since we do not discriminate whom our patients are and because our service is a human right. But let us not deceive ourselves. We all have implicit bias and many doctors are better at suppressing it and deny its impact.

You may blame a young Black male for his circumstances that led to him getting shot. But let us look at it from a different perspective and try to understand why so many Black men shed their blood in trauma rooms across North America.

When a young Black male arrives in the ED with a gunshot wound, for those whom the stereotype applies, there is always a story that informs how he ended up there. The story often begins when he was a young child about to enter the school system and a series of questions are asked about his early childhood experiences such as; what programs and 
opportunities he was exposed to prior to entry into school? This is problematic in under-served racialized communities for a variety of reasons. Often the school's administration and staff are keenly aware of how he behaves early on and many begin to make assumptions about everything from his intellectual capabilities to his ability to self-regulate and conform to the rules of engagement necessary for success in the classroom. Is he able to sit quietly and engage in paper and pencil tasks? If not, he will be excluded from the classroom periodically. When this happens, the student falls behind and is referred to the special education program at the school. At this point, the student is deemed to have both a behavioural and a learning problem.

As he progresses through the grades, an Individual Education Plan is developed and he may ultimately be given a special education designation (despite the potential to score high on formal IQ testing) and offered a small classroom setting where he has very little or no access to a regular program with his peers. This experience often leads to disengagement and lack of interest in both school and learning. By this time, one or more suspensions have been issued, further excluding him from the classroom. It has been documented that upon completion of high school, $42 \%$ of Black students have been suspended at least once, compared with $18 \%$ of other students [1].

The school becomes a hostile environment for the young Black boy who is often feared and considered trouble.
Depending on the supports he has at home or in the community, he may be sought out by gangs who promise a sense of belonging and community that the school has failed to provide. There is a fork in the road and one path leads to guns, gangs, violence and potentially the trauma room.

Take a moment to reflect on your perception of Black males in the trauma room and on the systemic racism of Black boys in schools. Start to unpack your biases towards Black people. We all have a story to tell about our unique journey in life. The problem is that collectively Black people have a common shared experience in their journey called racism.

\section{Compliance with ethical standards}

Conflict of interest The authors declare no conflict of interest.

\section{Reference}

1. James CE, Turner T. Towards Race Equity in Education: the Schooling of Black Students in the Greater Toronto Area. York University. 2017. https://edu.yorku.ca/files/2017/04/TowardsRace-Equity-in-Education-April-2017.pdf. Accessed 15 June 2020 